\title{
TEKANAN DARAH BERDASARKAN POSISI FLAT ON BED, SEMIFOWLER DAN FOWLER PADA VARIASI KELOMPOK USIA
}

\author{
BLOOD PRESSURE BASED ON POSITION FLAT ON BED, SEMIFOWLER AND \\ FOWLER ON THE AGE GROUPS
}

\author{
Yunus Elon ${ }^{1}$, Ferdiansyah Marbun ${ }^{2}$ \\ Fakultas IImu Keperawatan Universitas Advent Indonesia \\ Email: yunus.elon@unai.edu
}

\begin{abstract}
ABSTRAK
Pendahuluan: Tekanan darah merupakan tanda vital untuk menentukan status kesehatan. banyak faktor yang mempengaruhi hasil pengukuran tekanan darah salah satunya adalah posisi tubuh. Pada peneitian ini akan diteliti hasil pengukuran tekanan darah setelah perubahan posisi yaitu pada posisi flat on bed, semifowler dan fowler. Tujuan: Tujuan penelitian ini adalah untuk mengidentifikasikan perbedaan hasil pengukuran tekanan darah pada perubahan posisi tubuh. Metode: metode observasi analitik dengan rancangan cross sectional. Populasi dalam penelitian ini adalah siswa/i SD, SMP dan mahasiswa Universitas Advent Indonesia yang di kategorikan dalam usia anak-anak, remaja dan dewasa. Teknik pengambilan sample yang digunakan purposive sampling dan diperoleh sampel sejumlah 69 orang. Penelitian ini dianalisa dengan menggunakan analisa statistik deskriftif dan uji T Berpasangan. Hasil: Hasil menunjukan nilai rata-rata tekanan darah sistolik dan diastolik posisi flat on bed 100.17/69.39, 108.39/73.35, 114.65/71.35 mmHg, posisi semifowler yaitu 99.52/72.43, 101.78/73.83, 112,61/72.87 $\mathrm{mmHg}$ dan posisi fowler yaitu 102.57/71.87, 108.22/75.74, $112.91 / 75.78 \mathrm{mmHg}$ berdasarkan kelompok usia anak-anak, remaja dan dewasa. Ada perbedaan hasil pengukuran tekanan darah sistolik dan diastolik pada posisi flat on bed dan semifowler ( $\mathrm{p}$ value $\leq 0.05$ ) dan diastolik posisi flat on bed dan fowler ( $p$ value $\leq 0.05$ ). Diskusi: Berdasarkan hasil penelitian dapat di nyatakan bahwa posisi sangat mempengaruhi tekanan darah, dimana semakin tinggi posisi kepala dari jantung maka akan semakin tinggi tekanan darah.
\end{abstract}

Kata kunci: flat on bed, semifowler, fowler, posisi tubuh tekanan darah.

\begin{abstract}
Introduction: Blood pressure is a vital sign to determine health status. Many factors that influence blood pressure measurement results one of them is the position of the body. In this research will be examined the results of blood pressure measurements after the change position ie on the position of flat on bed, semifowler and fowler. Purpose: The purpose of this study was to identify differences in blood pressure measurements on changes in body position. Method: The method for this research is using cross sectional design. The population in this study are students of SD, SMP and students of Advent Indonesia University who are categorized in the age of children, adolescents and adults. Sampling technique used purposive sampling and obtained a sample of 69 people. This study was analyzed using descriptive statistical analysis and $T$ paired test. Result: The results show the mean values of systolic and diastolic blood pressure on the flat bed position of 100.17 / 69.39, 108.39 / 73.35, $114.65 / 71.35$ $\mathrm{mmHg}$, the semifowler position of 99.52 / 72.43, 101.78 / 73.83, $112.61 / 72.87 \mathrm{mmHg}$ and the fowler position of $102.57 / 71.87,108.22$ / 75.74, $112.91 / 75.78 \mathrm{mmHg}$ by age group of children, adolescents and adults. There were differences in systolic and diastolic blood pressure measurements on the flat on bed and semifowler ( $p$ value $\leq 0.05$ ) and diastolic positions of flat on bed and fowler ( $p$ value $\leq 0.05$ ). Discussion: Based on the research results can be stated that the position greatly affects blood pressure, where the higher the head position of the heart then the higher the blood pressure.
\end{abstract}

Key words: blood pressure, body position, flat on bed, semifowler, fowler.
JURNAL

\section{SKOLASTIK} KEPERAWATAN

Vol, 3, No. 2

Juli - Desember 2017

ISSN: $2443-0935$ E-ISSN 2443 - 1699 


\section{PENDAHULUAN}

Pengukuran tekanan darah merupakan keterampilan klinis yang penting untuk perawat. Potensi untuk kesalahan yang buruk dapat mempengaruhi menejemen pengukuran, apabila semua prosedur ini tidak di ikuti dengan hati hati perawat dapat melakukan pengukuran tekanan darah dengan menggunakan merkuri konvensional atau sphygmomanometer aneroid dan monitor tekanan darah elektronik. Hal ini juga mengidentifikasi sebagai sumber potensial dalam pengukuran tekanan darah. (Wallymahmed, 2008)

Green, (2008) menyatakan karena pengaruh gravitasi, tekanan darah akan meningkat dangan $10 \mathrm{mmHg}$ setiap 12 $\mathrm{cm}$ di bawah jantung. Di atas jantung, tekanan darah akan menurun dengan jumlah yang sama. Jadi dalam keadaan berdiri, maka tekanan darah sistole adalah $210 \mathrm{mmHg}$ di kaki tetapi hanya $90 \mathrm{mmHg}$ di otak. Dalam keadaan berbaring

kedua tekanan ini akan sama. Nilai pada posisi berbaring dalam keadaan istirahat hampir sama dengan nilai maksimal yang diperoleh pada waktu kerja dengan posisi berdiri. Jumlah isi sekuncup pada orang dewasa laki-laki mempunyai variasi antara $70-100 \mathrm{ml}$.

Makin besar intensitas kerja (melebihi batas $85 \%$ dari kapasitas kerja) makin sedikit isi sekuncup; hal ini di sebabkan memendeknya waktu pengisian diastole akibat frekuensi denyut jantung yang meningkat (bila mencapai 180/menit maka 1 siklus jantung hanya berlangsung selama 0,3 detik dan pengisian diastole merupakan bagian dari 0,3 detik tersebut) (Guyton, 2007). Hasil dari pengukuran tekanan darah di pengaruhi beberapa faktor, yaitu aktivitas yang akan dilakukan sebelum pengukuran, tekanan stress yang akan di alami, posisi saat pengukuran berdiri atau duduk, serta waktu pengukuran (Yasmine, 2007)

Hasil penelitian yang dilakukan di Universitas Sam Ratulangi Manado (2015) menunjukan terdapat perbedaan hasil pengukuran tekanan darah antara posisi duduk dan posisi berdiri. Tekanan darah sistolik atara posisi duduk vs posisi berdiri $117,984+\ldots 12,5877 \mathrm{mmHg}$ vs $124,7302+11,9546 \mathrm{mmHg}$ dan tekanan darah diastolik antara posisi duduk vs berdiri 79,2698+9,0656 $\mathrm{mmHg}$ vs $87,5238+8,6639 \mathrm{mmHg}$ yang menyatakan bahwa tekanan darah posisi berdiri cenderung tinggi di banding posisi duduk.

Berdasarkan latar belakang diatas, tekanan darah dipengaruhi oleh berbagai keadaan salah satunya adalah perubahan posisi tubuh. Oleh sebab itu, peneliti tertarik untuk melakukan penelitian tentang "TEKANAN DARAH BERDASARKAN POSISI FLAT ON BED, SEMIFOWLER DAN FOWLER PADA VARIASI KELOMPOK USIA"

\section{BAHAN DAN METODE}

Alat-alat yang digunakan dalam penelitian ini adalah Spygmomanometer digital, sebagai alat untuk mengukur tekanan darah.Baterai toshiba, dan ABC sebagai daya untuk spygmomanometer digital. Alat ukur derajat posisi tubuh/ busur derajat. Jam tangan, sebagai alat untuk mengukur waktu yang di gunakan. Lembar observasi dan alat tulis, sebagai media dokumentasi selama proses penelitian yang akan di lakukan. Laboratorium Fakultas keperawatan 
Universitas Advent Indonesia. Populasi yang diteliti dalam penelitian yang dilakukan adalah variasi kelompok usia yaitu anak-anak, remaja dan dewasa. Subjek penelitian ini masing masing berjumlah 23 orang responden di lingkungan Universitas Advent Indonesia. Pengambilan sampel di lakukan dengan teknik purposive sampling, yaitu teknik penetapan sample dengan cara memilih sampel diantara populasi sesuai dengan kehendak peneliti, sehingga sampel tersebut dapat mewakili karakteristik populasi yang telah dikenal sebelumnya.

\section{HASIL}

Tabel 1. Nilai rata- rata tekanan darah posisi flat on bed, semifowler dan fowler pada kelompok usia anak- anak.

\begin{tabular}{lccc}
\hline \multicolumn{1}{c}{ Pasisi } & n & $\begin{array}{l}\text { Rerata } \\
(\mathrm{mmhg}) \\
\text { sistalik }\end{array}$ & dekanan darastalik \\
\hline Flat an bed & 23 & 100.17 & 69.39 \\
Semifowler & 23 & 99.52 & 72.43 \\
Fowler & 23 & 102.57 & 71.87 \\
\hline
\end{tabular}

Tabel 2. Nilai rata- rata tekanan darah posisi flat on bed, semifowler dan fowler pada kelompok usia remaja.

\begin{tabular}{lccc}
\hline \multicolumn{1}{c}{ Pasisi } & n & $\begin{array}{c}\text { Rerata tekanan darah } \\
\text { (mmhg) } \\
\text { sistalik }\end{array}$ & diastolik \\
\hline Flat an bed & 23 & 108.39 & 73.35 \\
Semifawler & 23 & 101.78 & 73.83 \\
Fowler & 23 & 108.22 & 75.74 \\
\hline
\end{tabular}

Tabel 3. Nilai rata- rata tekanan darah posisi flat on bed, semifowler dan fowler pada kelompok usia dewasa.

Posisi $\quad \pi \quad \begin{aligned} & \text { Rerata tekanan darah } \\ & (\mathrm{mmhg})\end{aligned}$

\begin{tabular}{lccc}
\hline & & sistalik & diastalik \\
Flat an bed & 23 & 114.65 & 71.35 \\
Semifawler & 23 & 112.61 & 72.87 \\
Fowler & 23 & 112.91 & 75.78 \\
\hline
\end{tabular}

Tabel 4. paired samples t-test Tekanan Darah antara Posisi Flat on bed, Semifowler dan Fowler

\begin{tabular}{|c|c|c|c|c|}
\hline Variabel & $\begin{array}{l}\text { Mea } \\
\pi\end{array}$ & Sd & $\begin{array}{l}\text { Sig } \\
\text { (2taied } \\
\text { ) }\end{array}$ & $\begin{array}{l}\text { interpretas } \\
\text { i }\end{array}$ \\
\hline $\begin{array}{l}\text { Sistalik } \\
\text { flat an bed } \\
\text { - sistalik } \\
\text { semifawle } \\
\Gamma\end{array}$ & $3.10 \mid$ & 8.604 & .004 & Signifikan \\
\hline $\begin{array}{l}\text { sistalik } \\
\text { semifowle } \\
\Gamma-\text { sistolik } \\
\text { fowler }\end{array}$ & $\begin{array}{l}3.26 \\
1\end{array}$ & $\begin{array}{l}10.29 \\
8\end{array}$ & .011 & $\begin{array}{l}\text { Tidak } \\
\text { signifikan }\end{array}$ \\
\hline $\begin{array}{l}\text { Sistalik } \\
\text { flat on bed } \\
-\quad \text { sistolik } \\
\text { fowler }\end{array}$ & 159 & 9.887 & .894 & $\begin{array}{l}\text { Tidak } \\
\text { signifikan }\end{array}$ \\
\hline $\begin{array}{l}\text { Diastalik } \\
\text { flat on bed } \\
\text { - diastolik } \\
\text { semi } \\
\text { fowler }\end{array}$ & 1.681 & 8.152 & . & $\begin{array}{l}\text { Tidak } \\
\text { signifikan }\end{array}$ \\
\hline $\begin{array}{l}\text { Diastalik } \\
\text { semi } \\
\text { fowler - } \\
\text { diastalik } \\
\text { fowler }\end{array}$ & $\begin{array}{l}1.42 \\
0\end{array}$ & 9.492 & .281 & $\begin{array}{l}\text { Tidak } \\
\text { signifikan }\end{array}$ \\
\hline $\begin{array}{l}\text { Diastalik } \\
\text { flat on bed } \\
\text { - diastolik } \\
\text { fowler }\end{array}$ & $3.10 \mid$ & 8.582 & .004 & signifikan \\
\hline
\end{tabular}

\section{PEMBAHASAN}

Nilai rata-rata tekanan darah posisi flat on bed, semifowler dan fowler berdasarkan usia anak-anak. Nilai ratarata hasil pengukuran tekanan darah posisi flat on bed sistolik $100.17 \mathrm{mmHg}$ dan diastolik $69.39 \mathrm{mmHg}$ yang di 
interpretasikan sebagai tekanan darah normal, sedangkan posisi semifowler sistolik $99.52 \mathrm{mmHg}$ dan diastolik 72.43 $\mathrm{mmHg}$ yang di intepretasikan sebagai tekanan darah normal serta posisi fowler memliki sistolik $102.57 \mathrm{mmHg}$ dan diastolik $71.87 \mathrm{mmHg}$. Dimana nilai rata-rata hasil pengukuran tekanan darah tertinggi sistolik di dapatkan pada posisi fowler yaitu $102.57 \mathrm{mmHg}$ sedangkan diastolik tertinggi di dapatkan pada posisi semifowler yaitu $72.43 \mathrm{mmHg}$.

nilai rata-rata tekanan darah posisi flat on bed, semifowler dan fowler berdasarkan usia remaja. Nilai rata- rata hasil pengukuran tekanan darah posisi flat on bed sistolik $108.39 \mathrm{mmHg}$ dan diastolik $73.35 \mathrm{mmHg}$ yang di interpretasikan sebagai tekanan darah normal, sedangkan posisi semifowler sistolik $101.78 \mathrm{mmHg}$ dan diastolik $73.83 \mathrm{mmHg}$ yang di intepretasikan sebagai tekanan darah normal serta posisi fowler memliki sistolik 108.22 $\mathrm{mmHg}$ dan diastolik $75.74 \mathrm{mmHg}$. Dimana nilai rata-rata hasil pengukuran tekanan darah tertinggi sistolik di dapatkan pada posisi flat on bed yaitu $108.39 \mathrm{mmHg}$ sedangkan diastolik tertinggi di dapatkan pada posisi fowler yaitu $75.74 \mathrm{mmHg}$.

nilai rata-rata tekanan darah posisi flat on bed, semifowler dan fowler berdasarkan usia dewasa. Nilai rata- rata hasil pengukuran tekanan darah posisi flat on bed sistolik $114.65 \mathrm{mmHg}$ dan diastolik $71.35 \mathrm{mmHg}$ yang di interpretasikan sebagai tekanan darah normal, sedangkan posisi semifowler sistolik $112.61 \mathrm{mmHg}$ dan diastolik $72.87 \mathrm{mmHg}$ yang di intepretasikan sebagai tekanan darah normal serta posisi fowler memliki sistolik 112.91 $\mathrm{mmHg}$ dan diastolik $75.78 \mathrm{mmHg}$. Dimana nilai rata-rata hasil pengukuran tekanan darah tertinggi sistolik di dapatkan pada posisi flat on bed yaitu $114.65 \mathrm{mmHg}$ sedangkan diastolik tertinggi di dapatkan pada posisi fowler yaitu $75.78 \mathrm{mmHg}$.

Tekanan darah di pengaruhi volume darah dan elastisitas pembuluh darah, peningkatan tekanan darah disebabkan peningkatan volume darah atau elastisitas pembuluh darah. Sebaliknya, penurunan volume darah akan menurunkan tekanan darah

hasil pengolahan data di atas menunjukan ada perbedaan hasil pengukuran tekanan sistolik pada posisi flat on bed dan semifowler ( $p$ value < 0.05), tidak ada perbedaan hasil pengukuran sistolik pada posisi semifowler dan fowler ( $p$ value > 0.05 ), tidak ada perbedaan pengukuran sistolik pada posisi flat on bed dan fowler ( $p$ value > 0.05) sedang kan pengukuran diastolik pada posisi flat on bed dan semifowler tidak terdapat perbedaan ( $p$ value > 0.05), posisi semifowler dan fowler diastolik tidak ada perbedaan ( $p$ value > 0.05) dan posisi flat on bed dan fowler terdapat perbedaan hasil pengukuran diastolik ( $p$ value $<0.05$ )

Analisis diatas menunjukan bahwa hasil pengukuran tekanan darah pada ketiga posisi tersebut memiliki perbedaan pada kelompok usia, apabila sebelum dilakukan pengukuran telah di minimalkan faktor-faktor lain yang dapat mempengaruhi hasil pengukuran tekanan darah terutama aktivitas serta perubahan posisi tubuh secara tiba-tiba. Dan sebagian besar memberikan kesimpulan bahwa tidak ada perbedaan bermakna pada hasil pengukuran tekanan darah untuk tiap posisi yang berbeda, namun perbedaan yang di berikan berupa peningkatan tekanan darah, maka hasil penelitian di atas menguatkan teori yang di kemukakan 
Green, (2008) menyatakan tekanan darah akan meningkat dengan $10 \mathrm{mmHg}$ setiap $12 \mathrm{~cm}$ di bawah jantung karena pengaruh gravitasi. Di atas jantung, tekanan darah akan menurun dengan jumlah yang sama.

Tekanan darah dalam ateri pada orang dewasa dalam keadaan duduk atau posisi berbaring pada saat istirahat kira- kira 120/70 mmHg. Karena tekanan darah adalah akibat dari curah jantung dan resistensi perifer, maka tekanan darah dipengaruhi oleh keadaan- keadaan yang mempengaruhi setiap atau dan isi sekuncup.

Tekanan darah terjadi karena ada dua kekuatan, satu kekuatan di ciptakan oleh jantung ketika ia memompa darah menuju pembuluh arteri dan melalui sistem sirkulatori. Sedangkan kekuatan yang lain adalah kekuatan pembuluh arteri ketika mereka mendesak darah mengalir ke jantung (Ramadhan, 2010). Ketika berbaring maka jantung akan berdetak lebih sedikit hal ini disebabkan efek gravitasi pada orang berbaring berkurang dibanding orng berdiri atau duduk sehingga membuat lebih banyak darah mengalir kembali kejantung melalui pembuluh darah (Guyton, 2002 dalam Anggita, 2012)

Posisi fowler dapat di gunakan untuk mengurangi tekanan darah kerena mengurangi aliran darah balik kejantung yang dipengaruhi oleh gaya gravitasi karena semakin banyak darah yang masuk kejantung semakin jantung berkontraksi yang menyebabkan tekanan darah (Tilkian dan Conover, 2011).

peningkatan tekanan darah disebabkan peningkatan volume darah atau elastisitas pembuluh darah. Sebaliknya, penurunan volume darah akan menurunkan tekanan darah.

\section{KESIMPULAN}

Rata-rata tekanan darah berdasarkan posisi tubuh flat on bed, semifowler dan fowler pada variasi kelompok usia, dapat disimpulkan rata-rata tekanan darah usia anak-anak adalah flat on bed 100.17/69.39 $\mathrm{mmHg}$, semifowler 99.52/72.43 $\mathrm{mmHg}$ dan fowler $102.57 / 71.87 \mathrm{mmHg}$. Untuk remaja nilai rata-rata tekanan darahnya adalah flat on bed 108.39/73.35 $\mathrm{mmHg}$, semifowler $101.78 / 73.83 \mathrm{mmHg}$ dan fowler 108.22/75.74 mmHg, sedangkan dewasa nilai rata-ratanya adalah flat on bed $114.65 / 71.35 \mathrm{mmHg}$, semifowler 112.61/ $72.87 \mathrm{mmHg}$ dan fowler $112.91 / 75.78 \mathrm{mmHg}$. Dapat di nyatakan bahwa posisi sangat mempengaruhi tekanan darah, dimana semakin tinggi posisi kepala dari jantung maka akan semakin tinggi tekanan darah.

Ada perbedaan signifikan hasil pengukuran tekanan sistolik pada posisi flat on bed dan semifowler,tidak ada perbedaan signifikan hasil pengukuran sistolik pada posisi semifowler dan fowler, tidak ada perbedaan signifikan pengukuran sistolik pada posisi flat on bed dan fowler, sedang kan pengukuran diastolik pada posisi flat on bed dan semifowler tidak terdapat perbedaan, posisi semifowler dan fowler diastolik tidak ada perbedaan dan posisi flat on bed dan fowler terdapat perbedaan signifikan tekanan darah diastolik. Implikasi dari penelitian ini adalah: posisi flat on bed sangat di rekomendasikan untuk melakukan pengukuran tekanan darah karena posisi tersebut memiliki hasil yang cenderung normal dan sangat di rekomendasikan bagi penderita hipertensi. 


\section{SARAN}

Mahasiswa di Universitas Advent Indonesia, dapat menggunakan dan memanfaatkan penelitian ini sebagai pengetahuan tambahan mengenai tekanan darah terhadap berbagai posisi tubuh.

Rumah sakit, Klinik, puskesmas dan layanan kesehatan lainnya dapat menjadikan ini sebagai acuan bahwa tekanan darah dapat di pengaruhi oleh posisi tubuh itu sendiri sehingga dapat menjadi ilmu pengetahuan tambahan.

Hasil penelitian dapat menjadi acuan serta pengembangan lanjutan untuk penelitian selanjutnya dan peneliti selanjutnya harus melakukan teknik lain dalam melakukan pengukuran tekanan darah ini yaitu pengukuran tekanan darah berdasarkan posisi tubuh untuk penderita hipertensi.

\section{DAFTAR PUSTAKA}

Anggara, FHD., (2013). Faktor- Faktor yang Berhubungan dengan Tekanan Darah di Puskesmas Telaga Murni. Cikarang Barat Tahun 2012 Jurnal Ilmiah Kesehatan, Vol 5 No. 1.

Anggita., (2012). Pengaruh Posisi Tubuh dengan Tekanan Darah. Jakarta: EGC.

Alimul, A., (2007). Riset Keperawatan \& Teknik Penulisan Ilmiah. Jakarta: Salemba Medika.

Alimul Aziz, H., (2008: 74). Pengantar Konsep Dasar Keperawatan. Edisi 2. Jakarta: Salemba Medika.

Arikunto, S., (2010). Prosedur Penelitian Suatu Pendekatan Praktik. Jakarta: PT Rineka Cipta.
Asmadi., (2008). Teknik Prosedural Keperawatan Konsep dan Aplikasi Kebutuhan Dasar. Jakarta: Salemba Medika.

Berman, A., (2009). Buku Ajar Praktik Keperawatan Klinis Kozier \& Erb, Alih Bahasa Meiliya dkk, EGC, Jakarta.

Cameron, J. R., (2008). Fisika Tubuh Manusia. Jakarta: EGC.

Campbell, N.A., (2007). Biologi.Edisi ke -5 jilid 3. Erlangga.

Epstein E., (2008). Mineral Nutrition of Plants: Principles dan Perspectives. New York.

E. St Harahap, dkk., (2007). Kamus Besar Bahasa Indonesia. Bandung: Balai Pustaka.

Ganong, W. F., (2008). Buku Ajar Fisiologi Kedokteran. EGC. Jakarta.

Gunawan, L., (2008). Hipertensi: Tekanan Darah Tinggi. Kansius: Yogyakarta

Guyton, A.C., (2007). Buku Ajar Fisiologi Kedokteran. Edisi 9. Jakarta: EG

Guyton, A. C., \& Hall, J. E., (2010). Buku Ajar Fisiologi Kedokteran. Edisi 11 jakarta: EGC.

Green, H.J., (2008). Fisiologi Kedokteran. Bina Aksara Rupa. Jakarta.

Herlambang., (2013). Hipertensi dan Diabetes. Jakarta selatan. Tugu Publisher. 
Hidayat. A., (2008). Metode Penlitian Keperawatan dan Teknik Analisa Data. Jakarta: Salemba Medika.

Irenawati., (2012). Purwarupa Tensimeter Digital Berbasis Atmega8 Menggunakan Sensor Tekanan MPX2100DP, Tugas Akhir, Program Diploma Elektronika dan Instumentasi, Sekolah Vokasi, Universitas Gadjah Mada, Yogyakarta.

Istiqomah, T., (2009). Pengukuran Tekanan Darah. Retrieved from http:/www.scribd.com/doc/5858 2610/Pengukuran Tekanan Darah: Diunduh 21 Maret 2013.

Kowalski, R.E., (2010). Terapi Hipertensi: Program 8 Minggu Menurunkan Tekanan darah Tinggi dan Mengurangi Resiko Serangan jantung dan Stroke secara Alami. Dialih bahasakan oleh Ekawati RS. Bandung: Qanita

Kozier, B., (2009: 222). Buku Ajar Praktik Keperawatan Klinis Kozier Erb. Jakarta: EGC.

Lumbantobing, S.M., (2008). Tekanan Darah Tinggi. Jakarta: Fakultas Kedokteran Universitas Indonesia.

Marliani, L., (2007). 100 Question \& Answers Hipertensi. Jakarta: Gramedia.

Miller, C., (2010). Factors Affecting Blood Preasure and Heart Rate. Available from: http://www.livestrong.com/articl e/196479-factors-affectingblood-pressure-heart-ratel [Accessed 5 may 2012].
Muhammadun., (2010). Hidup Bersama Hipertensi Seringai Darah Tinggi Sang Pembunuh Sejati. Jokjakarta: In-Books.

Palmer A, W.B., (2007). Tekanan Darah Tinggi. Jakarta: Erlangga.

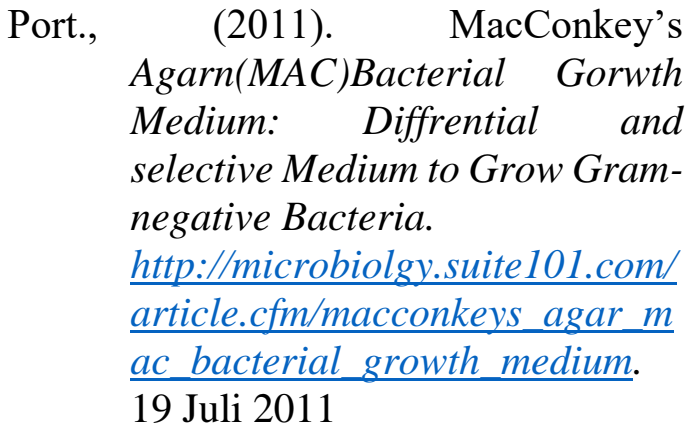

Potter, Patricia A., \& Anne Griffin Perry., (2005: 78). Buku Ajar Fundamental Keperawatan: Konsep, proses, dan Praktik, Edisi 4, Volume II. Jakarta: EGC.

Ramdan, A. J., (2010). Mencermati Berbagai Gangguan pada Darah dan Pembuluh Darah. Yogyakarta: Diva Press.

Ridwan, M., (2009). Mengenal dan Mencegah Hipertensi. Semarang: pustaka Widyamara
Ronny., (2008). Fisiologi Kardiovaskular: Berbasis Masalah Keperawatan. Buku Kedokteran: EGC.

Setiadi., (2007). Konsep dan Penulisan Riset Keperawatan.Yogyakarta: Graha Ilmu.

Sugiharto Aris., (2007). Faktor- Faktor Resiko Hipertensi Grade II pada Masyarakat di Kabupaten Karanganyar, Tesis Undip, Semarang. 
Sunyoto, D., (2012). Statistik Kesehatan. Yogyakarta: Nuha Medika.

Suparmi, Yulia., (2010: 25). Kebutuhan Dasar Manusia. Yogyakarta: PT Citra Aji Parama.

Tilkian, Ara G \& Mary Boudreau Conover., (2011). Memahami Bunyi dan Bising Jantung.Tangerang: Binarupa Aksara.

Wallymahmed, M., (2008). Blood Pressure Measurement. Nursing standart.

Yasmine, E., (2007). Simple Guide Tekanan Darah Tinggi. In $A$. Palmer, A simple Guide Blood Preassure. Indonesia: Erlangga.

Yogiantoro, M., (2008). Hipertensi Esensial. Dalam: Sudoyo, A.W., Setiyohadi, B., Alwi, I., Simadibrata, K., Setiadi, S., eds. Buku Ajar Ilmu Penyakit Dalam. Jilid 1. Edisi IV. Jakarta: Pusat Penerbitan Departemen Ilmu Penyakit Dalam FK UI, 599. 